\title{
Numerical modelling of drop load tests
}

\author{
R. Colombero ${ }^{1}$, S. Kontoe ${ }^{2}$, S. Foti ${ }^{3}$ \& D.M. Potts ${ }^{4}$ \\ 1 Corresponding Author: Formerly, Department of Civil and Environmental Engineering, Imperial College London, South \\ Kensington Campus, London SW7 2AZ, UK. E-mail: raffaella.colombero12@alumni.imperial.ac.uk \\ ${ }^{2}$ Senior lecturer, Department of Civil and Environmental Engineering, Imperial College London, South Kensington Campus, London \\ SW7 2AZ, UK. Tel: +44 (0)20 7594 5996; E-mail: stavroula.kontoe@imperial.ac.uk \\ ${ }^{3}$ Professor, Department of Structural, Geotechnical and Building Engineering, Politecnico di Torino, C.so Duca degli Abruzzi 24, \\ 10129 Torino, Italy. Tel: +39 011090 4896; E-mail: sebastiano.foti@ polito.it \\ ${ }^{4}$ Professor, Department of Civil and Environmental Engineering, Imperial College London, South Kensington Campus, London \\ SW7 2AZ, UK. Tel: +44 (0)20 7594 6084; E-mail: d.potts@imperial.ac.uk
}

\begin{abstract}
Assessment of the attenuation of induced vibrations in the ground plays an important role in evaluating comfort and structural safety. Analytical and empirical wave attenuation relationships of increasing complexity and detail are presented in the paper, as well as a numerical model that accurately reproduces wave attenuation for a well-documented site, namely the one of the Tower of Pisa, Italy. A new source model is calibrated on near-field data and used as input for the dynamic coupled consolidation Finite Element Analysis to achieve a satisfactory simulation. The accuracy of simpler analytical and empirical approaches is then comprehensively assessed through comparison with the validated numerical model and the field data obtained from geophones at various distances from the impact source.
\end{abstract}

Keywords: ground vibrations, wave propagation, attenuation, finite element method, surface waves

\section{Introduction}

Ground vibrations caused by human activities may have an adverse effect on structural safety and comfort. Numerical analyses of induced vibration can play an important role in establishing the expected amplitude of ground vibrations for a variety of circumstances such as for example construction works, soil improvement by compaction, blasting, and industrial activities. In this paper, drop load tests are used to calibrate a numerical model and study the expected attenuation of ground vibration.

It is generally difficult to establish the reduction of the vibration amplitude with distance. Both geometrical and material attenuation are of great importance in the soil response, as well as soil layering, groundwater conditions and the surrounding environment. Geometrical wave spreading, material damping and scattering due to heterogeneities in the soil all contribute to vibration attenuation in the ground: the first component follows a power law with distance, the latter two follow an exponential law (Auersch, 2010). In this study, the decay of peak particle velocity with distance of impact-induced vibrations is thoroughly analysed and the power trend is found dominant in many empirical vibration attenuation laws. Data collected in Pisa, Italy, are reviewed to evaluate the capabilities of wave amplitude vs. distance relationships.

Drop load sources are often used in surface wave analysis for site characterisation (Foti et al., 2014). These tests are non-intrusive and can be used to obtain shear wave velocity and material damping profiles at a site. Several analytical expressions have been developed in the past to reproduce the source pulse generated by the drop load test (Pekeris, 1955, Mooney, 1974, and Abe et al., 1990). However, only a few of these provide a good match to real data. A more refined expression for the source signal is proposed herein, based on

${ }^{1}$ Permanent address: Atkins Ltd, The Wells, Church Street, Epsom KT17 4PF, UK. Tel: +44 (0)20 77553770. 
experimentally recorded signals, to be used as input for the numerical simulation. It implicitly considers the influence of the characteristics of the drop load apparatus on the resultant seismic wave field. This approach can be easily extended to calibrate the source model for other activities inducing ground vibrations on the basis of experimental data collected in the vicinity of the source.

Previous numerical simulations of Spectral Analysis of Surface Waves (SASW) tests were performed to evaluate the potential influence of the test setup and soil stratigraphy on the ground frequency response in terms of dispersion curves through comparison with experimental tests (Gucunski and Woods, 1992). For this study, numerical simulations of the Pisa field tests were carried out. The layered soil profile was modelled in detail and the drop load was simulated with the newly proposed expression for the source pulse. The velocity time histories were computed at several distances from the falling weight and compared to the experimental recordings. Focus was given to the wave decay with distance. As a realistic peak particle velocity (PPV) decay with distance was obtained, the finite element model is deemed to be reliable in reproducing the dissipation of the energy generated by drop load tests. This approach may be a useful tool in place of the empirical expressions for wave attenuation if a sufficient knowledge of the site is available.

\section{Amplitude-distance attenuation laws}

\subsection{Theoretical framework}

Any disturbing source acting on a medium generates a complex wave field within it. The amplitude of such waves decays with distance as the waves propagate away from the source. It is well established that three main mechanisms influence the attenuation of impact-induced wave fields, as reported in many studies after the pioneering work of Lamb in 1904 (e.g. Semblat \& Pecker, 2009; Auersch, 2010):

- Geometrical attenuation. Waves generated at a point propagate in the soil with a continuously expanding front, a hemisphere and a cylinder for body waves and Rayleigh waves respectively. Neglecting dissipative components, the wave energy remains constant along the wave front; hence the energy per unit area of the wave front decreases as the wave travels from the source point. As the peak particle amplitude attenuation is linked to the energy decay, the amplitude-distance relationship is based on the elastic wave energy conservation and follows a power law $\mathrm{A} \propto \mathrm{r}^{-\mathrm{n}}$, where $A$ represents the amplitude of a recorded quantity of the wave motion (e.g. velocity or acceleration) and $r$ is the distance from the source position. The exponent $n$ is equal to 0.5 and 2.0 respectively for surface and body waves produced by a surface point load.

- Material attenuation. The hysteretic behaviour of the soil leads to a second attenuation component, exponentially dependent on the distance, $A \propto \exp \left(-k_{M} \cdot r\right)$, where the attenuation coefficient $k_{M}$ can be expressed as a function of the soil damping ratio $\xi$, the wave frequency $\omega$ and Rayleigh wave propagation velocity $V_{R}$.

- Scattering in non-homogeneous media. In heterogeneous media, due to a change in the material properties at the interfaces between successive layers, the waves are reflected and refracted. As a consequence of this, the distribution of wave energy is locally modified and the wave amplitude reduces. Similarly to the material damping relationship, the scattering attenuation with distance follows an exponential law, where the attenuation coefficient $k_{S}$ is inversely proportional to the shear wavelength $\lambda_{s}$.

Auersch (2010) proposed the following peak particle amplitude attenuation law which incorporates all three mechanisms:

$$
A_{j}=A_{i}\left(\frac{r_{j}}{r_{i}}\right)^{-n} \exp \left[-k_{M} \cdot\left(r_{j}-r_{i}\right)\right] \exp \left[-k_{S} \cdot\left(r_{j}-r_{i}\right)\right]
$$

Where $A_{i}$ and $A_{j}$ are the amplitude of the wave motion at two points $i$ and $j ; r_{i}$ and $r_{j}$ are the corresponding distances from the source location; and $n, k_{M}$ and $k_{S}$ are the attenuation coefficients.

\subsection{Drop load tests and analytical representation of disturbing sources}

Drop load tests are often carried out as part of Spectral Analysis of Surface Waves (SASW) tests. They consist of a falling heavy weight hitting a plate or directly the ground, generating a wave field (Figure 1). Particle velocity signals are captured at different distances from the source by geophones (Figure 2). 


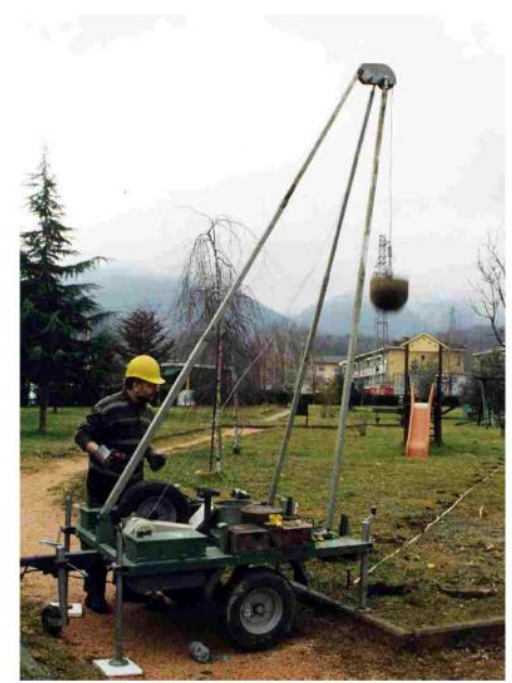

Figure 1-Drop load test apparatus used for experimental tests in Pisa

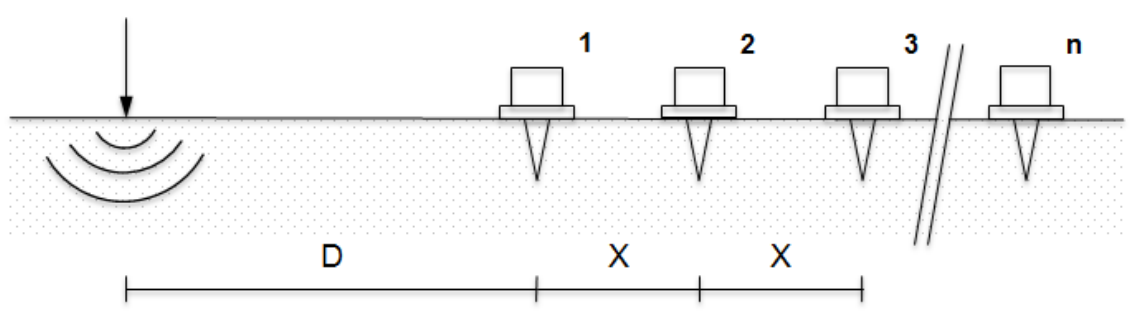

Figure 2 - Experimental setup for multistation SASW tests

A vertical point load acting on the surface of a half-space represents a good approximation of the falling mass used in drop load tests. Lamb (1904) presented a first attempt to evaluate the soil response due to a surface point force, representing the disturbance by a vertical impulse. Based on Lamb's work, several authors deduced complete analytical solutions in terms of particle displacements, velocities, accelerations and strains due to the application of an arbitrary excitation. For example, Pekeris (1955) assumed the source to be a Heaviside step unit function (Figure 3a), while Mooney (1974) considered a Dirac Delta function (Figure 3b). However in both cases the resulting velocity response reached non-realistic infinite values. Hence Mooney (1974) suggested an arbitrary sinusoidal function (Figure 3c), able to better predict the generated wave field. Abe et al. (1990) suggested a new sinusoidal expression (Figure 3d), which accounts for the effect of the drop load apparatus characteristics on the wave field by assuming the amplitude of the source signal to be proportional to the momentum of the weight before the impact (given by the product of mass by velocity just before the impact). 

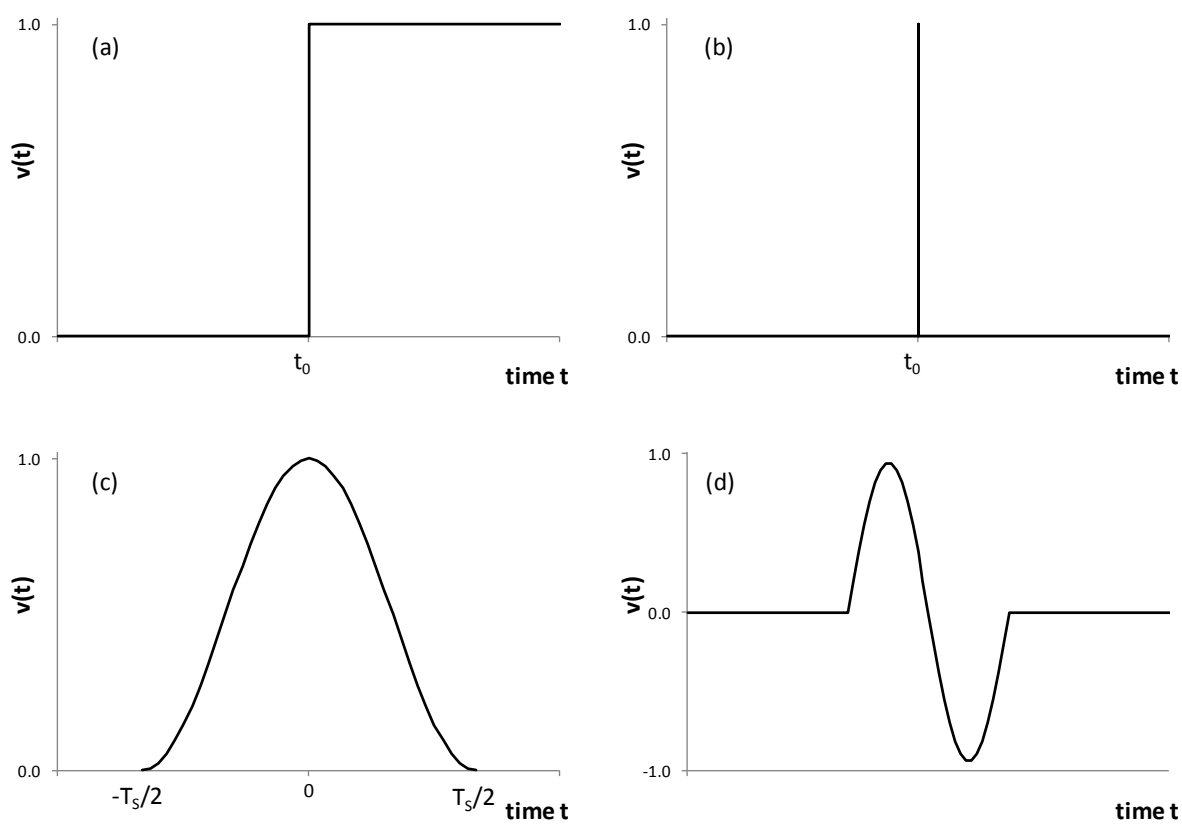

Figure 3 - Analytical source representations in terms of particle velocity: (a) Heaviside step unit function (Pekeris, 1955); (b) Dirac Delta function (Mooney, 1974); (c) Sinusoidal function (Mooney, 1974); and (d) Sinusoidal function (Abe et al., 1990)

Although the expression proposed by Abe et al. (1990) is quite representative of a drop load test action, it results from a parametric analysis of the influence of the standardised drop load tests setup on the recorded source signal. Therefore a more realistic approximation of the source pulse is still needed. Force identification procedures (Hollandsworth and Busby, 1989; Martin and Doyle, 1996) would provide a consistent framework to formulate an appropriate source model. Nevertheless, they require the solution of a rather complex inverse problem especially in the case of a drop-load test in which a significant plasticization is expected in the impact zone. The solution of the inverse problem would be in this case very computationally intensive and time consuming. Moreover, the non-uniqueness of the solution would represent a very serious issue. A simpler but efficient approach is proposed herein. The new source function is directly formulated on the basis of near-field observations of particle velocity time histories recorded by geophones positioned next to the drop-load source. The shape of waves propagating in the soil away from the source does not change significantly in the near-field, since no time for wave dispersion, reflections and refractions is allowed. Therefore the near-field data can be used to obtain a more accurate representation of the source. A Gabor wavelet (as presented in Semblat and Pecker, 2009) forms the basis of the new function which is modified to account for the momentum of the dropped weight $C_{b}$ in order to approximate the pulse produced by a mass falling on the ground (Figure 4).

All the above equations for the representation of the drop load source signal in terms of particle velocity are summarised in Table 1 in chronological order.

Table 1 - Drop load source signal analytical representations

\begin{tabular}{lll}
\hline Reference & Equation \\
\hline Pekeris (1955) & $v(\mathrm{t})= \begin{cases}1 & \mathrm{t} \geq \mathrm{t}_{0} \\
0 & \mathrm{t}<\mathrm{t}_{0}\end{cases}$ \\
Mooney (1974) & $v(t)= \begin{cases}\lim _{d t \rightarrow 0} \frac{1}{d t} \\
0\end{cases}$ \\
Mooney (1974) & $v(t)=H_{0}-\frac{d t}{2} \cos ^{2}\left(\frac{\pi t}{T_{S}}\right)$ & otherwise
\end{tabular}




$$
\begin{array}{lll}
\text { Abe et al. (1990) } & v(t)=\frac{2 \pi}{T_{S}} C \cdot C_{b} \cdot \operatorname{sen}\left(\frac{\pi}{T_{S}} t\right) \cos \left(\frac{\pi}{T_{S}} t\right) & 0 \leq t \leq T_{S} \\
\text { Current study } & v(t)=\left\{\begin{array}{cl}
C_{b} \cdot \beta \cdot t^{\gamma} \cdot \exp \left[-\left(\frac{2 \pi}{T_{S} \alpha} t\right)^{2}\right] \cos \left(\frac{2 \pi}{T_{S}} t\right) & 0 \leq t \leq 1.2 T_{S} \\
0 & \text { otherwise }
\end{array}\right.
\end{array}
$$

Where $t$ is a generic time instant, $t_{0}$ is a reference time, $d t$ an infinitesimal time period, $T_{S}$ and $H_{S}$ are the period and maximum amplitude of the function, $C, \alpha, \beta$, and $\gamma$ are constants and $C_{b}$ the momentum of the dropped weight.

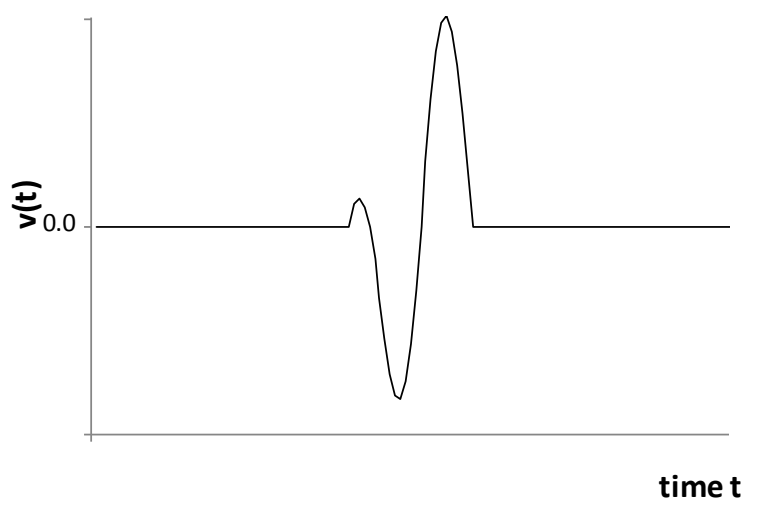

Figure 4-Modified Gabor wavelet

\subsection{Empirical amplitude-distance attenuation laws for waves induced by impact loads}

The attenuation of ground vibrations induced by impact sources can be simplistically approximated by a power law of the form $A \propto r^{-q}$, as it has been argued in the literature that the neglected exponential terms have only a minor influence as the distance increases (Auersch and Said, 2010). Various experimental velocity recordings have been analysed to assess the attenuation of impact-induced vibrations (Auersch, 2010, and Auersch and Said, 2010). The exponent $q$ was found to change according to the type of source. Also the type of soil profile has an influence on the empirical exponent: in soft soils higher particle velocity amplitudes are recorded in particular in the near-field and a stronger attenuation with distance is observed (Auersch and Said, 2010). Experimental exponents $q$ of 1.0 to 1.6 have been found for mass drop tests carried out on sandy and clayey soils respectively (Auersch, 2010), values which are considerably different from the theoretical geometrical exponents previously mentioned.

Mooney (1976) analysed the wavefield generated by a surface force comparing analytical and experimental analyses. He found that the amplitude parameters of the induced wavefield correlate with the distance $r$ from the disturbing source through a power law and with the characteristics of the source (pulse amplitude and period) as defined below:

$$
A=C \cdot H_{S} \cdot r^{-n} \cdot T_{S}^{-m-p}
$$

Where the source has pulse amplitude $H_{S}$ and period $T_{S} ; C$ is a constant; $m+p=1.4$ and $\mathrm{n}=0.5$ are the surface waves velocity exponents; and $r$ is the distance.

The complete theoretical attenuation law can also apply to the drop load tests case. Considering the power component formulation as defined in equation (7) and combining the two exponential terms:

$$
A=C \cdot H_{S} \cdot R^{-n} \cdot T_{S}{ }^{-m-p} \cdot \exp (-k R)
$$

Where $H_{S}, T_{S}, C$ and $m+p$ have been previously defined; $k=2 \pi \xi$ (with $\xi$ material damping); $\mathrm{n}$ is the effective surface wave velocity attenuation exponent; and $R=r / \lambda_{R}$, which represents the distance $r$ normalised by the surface waves wavelength $\lambda_{R}$.

Another equation to approximate the attenuation of peak particle velocity with distance, suggested by Sambuelli (2009), has been considered in this study. Originally conceived for blasting operations, it has been 
examined to investigate its possible application to drop load tests. Sambuelli's equation links the wave particle velocity $v$ with the distance normalised by the square root of the maximum charge per delay $Q$ [kg] (defining this way the scaled distance $S D=r / \sqrt{Q}$ ):

$$
v \cong 0.65 \frac{K}{S D}\left(\frac{2 \Phi r_{0} f}{r \rho V_{R}}\right)^{0.5}
$$

Where $\Phi$ is the explosive specific energy $[\mathrm{J} / \mathrm{kg}], f$ is the dominant frequency of the excitation, $\rho$ is the rock density, $r_{0}$ the diameter of the hole drilled to place the explosive and $V_{R}$ the surface wave velocity. The scaling factor 0.65 accounts for the $65 \%$ of energy carried by surface waves (Miller \& Pursey, 1955). Equation (9) is also an approximate power law, but blasting design, signal and rock characteristics and acquisition geometry are all taken into account. Moreover it is theoretically sound, as it is based on the specific features of Rayleigh waves which play the predominant role in the transmission of ground vibrations in the far field.

\section{Site description and field data}

The soil underlying the Tower of Pisa, sited in Piazza dei Miracoli, Pisa (Italy) has been extensively characterised in the last decades. These studies were conducted to determine a permanent and effective solution for the Tower instability (Burland et al., 2003; 2009). This comprehensive characterisation of the site makes it a good choice for the numerical analysis presented within this study.

\subsection{Site subsoil characterisation}

Information from in situ and laboratory tests has been gathered in several previous reports (particularly significant are the works of Jamiolkowski et al., 1993; Costanzo et al., 1994; Burland et al., 1998; Rampello and Callisto, 1998; Jamiolkowski and Pepe, 2001; Lo Presti et al., 2003). Among other tests, seismic crosshole tests have been performed to estimate the seismic velocities profiles (both for P-wave and S-wave) down to a depth of $65 \mathrm{~m}$.

The soil stratigraphy beneath Piazza dei Miracoli comprises the following formations: silty-clayey soil, manmade ground (MG); clayey and sandy yellow silts (A1); Upper Sand (A2); Upper Pancone Clay (BI); Intermediate Clay (BII); Intermediate Sand (BIII); Lower Clay (BIV); and Lower Sand (C). Typical layer depths are shown in Figure 5. The soil layers present approximately horizontal bedding.

The phreatic water table was found at a depth of 1.0 to $1.5 \mathrm{~m} \mathrm{bgl}$. The soil parameters retrieved from the tests will not be presented in this study for brevity.

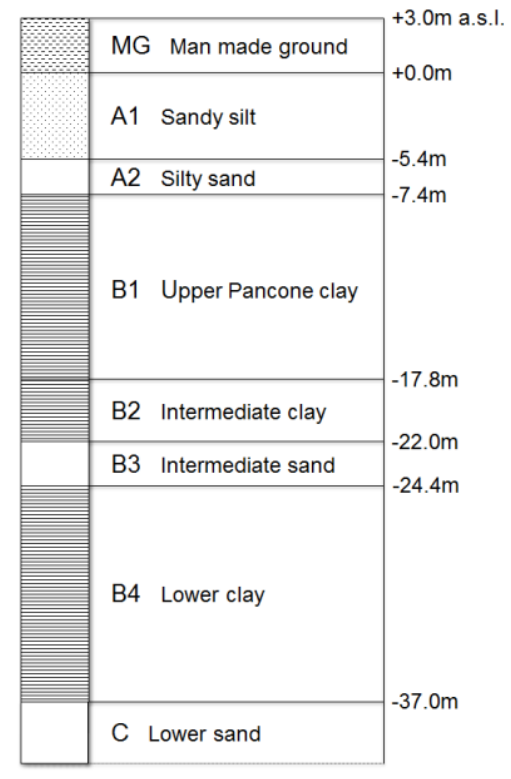

Figure 5 - Indicative stratigraphy retrieved in Piazza dei Miracoli, Pisa 


\subsection{Drop load tests performed in Piazza dei Miracoli}

Seismic Analysis of Surface Waves tests (SASW) were performed in Piazza dei Miracoli next to the Tower (Figure 6 and Foti, 2003) to gain a further subsoil description by means of seismic techniques. To cover a broad frequency range, two types of seismic sources were used: a sledge hammer and a heavy ball for the drop-load tests.

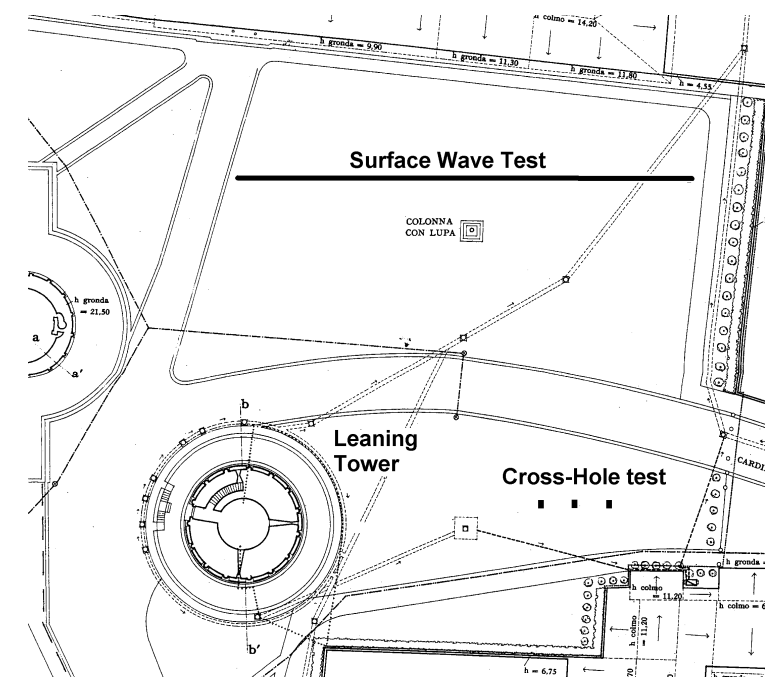

Figure 6-Location of seismic tests at the Leaning Tower of Pisa site

The drop load test configuration consisted of a $130 \mathrm{~kg}$ weight dropped from a height of approximately $3 \mathrm{~m}$, hitting the ground directly in order to avoid mass rebound and to reach lower frequencies (which are useful to characterise deeper layers). 24 in-line geophones were used in the tests, able to get reliable recordings of particle vertical velocity at frequencies greater than their resonant frequency $(4.5 \mathrm{~Hz})$. Low-frequency waves with a large wavelength are produced by a heavy source. Therefore the distance adopted between the receivers and between the source and the first receiver was $2.5 \mathrm{~m}$, generating a total array length of $60 \mathrm{~m}$ from the source location. Sampling rates of $0.002 \mathrm{~s}$ and total number of 2048 samples were used for the tests. Seven tests were undertaken to check the test repeatability, confirmed by comparing the different test results both in the time and frequency domains. It should be noted that in this study, one of the seven acquisitions has been taken as the reference one.

Figure 7 shows the velocity time histories recorded at 5,30 and 55m from the source location and the corresponding Fourier spectra. The recordings clearly highlight the dispersive nature of the Pisa soil profile. Since it is a layered profile, it exhibits an increasing shear wave velocity with depth, resulting in highfrequency (i.e. short-wavelength) components of surface waves propagating more slowly than the lowfrequency components and increasing the significant duration of the motion with distance. Moreover, a slight shift in the signal frequency content is observed, from predominant frequencies of $25 \div 35 \mathrm{~Hz}$ in the nearfield, to $10 \div 25 \mathrm{~Hz}$ going further away from the source location. 
Geophone No.2 $(r=5.0 \mathrm{~m})$
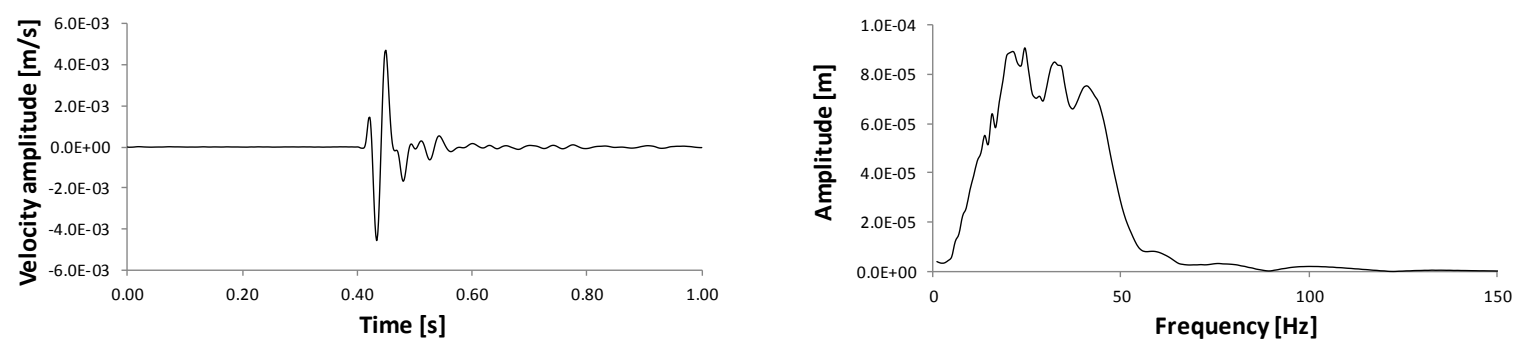

Geophone No.12 $(r=30.0 \mathrm{~m})$
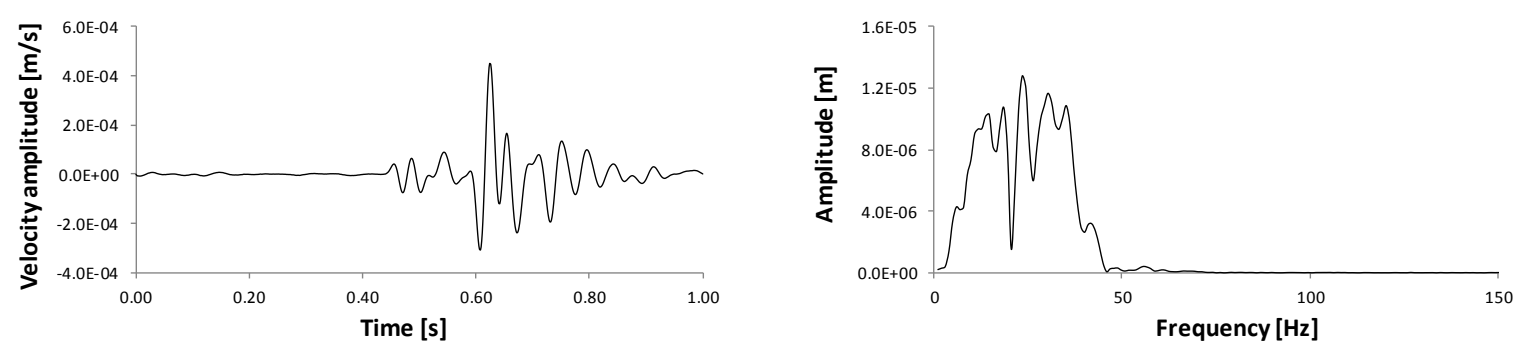

Geophone No.22 $(r=55.0 \mathrm{~m})$
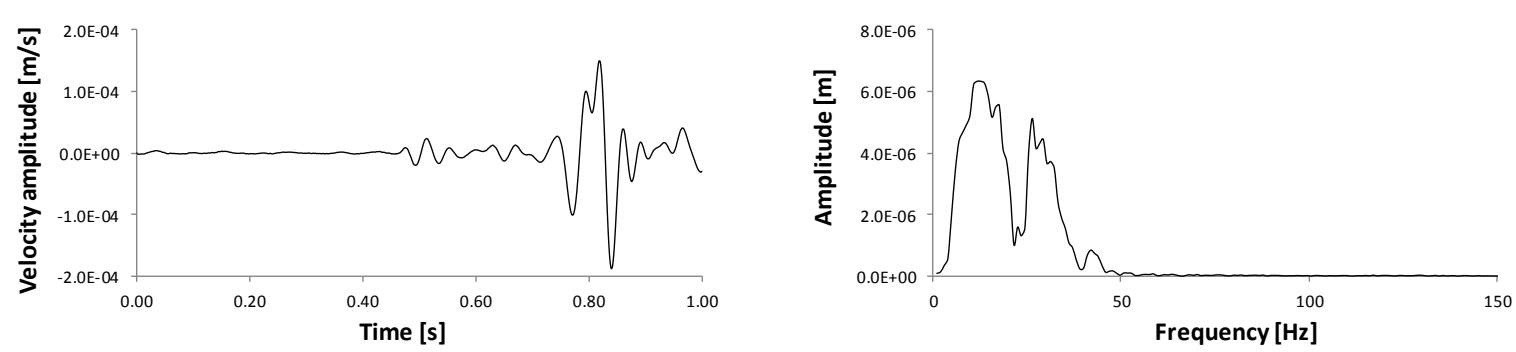

Figure 7 -Velocity time histories recorded at $r=5,30$ and $55 \mathrm{~m}$ from the source and corresponding Fourier spectra

The most common approach to analyse the attenuation of ground vibrations is to evaluate the peak particle velocities (PPVs) recorded by each geophone. These values are then plotted on a double logarithmic graph against the recording distance from the source. The magnitude of the peak particle velocities ranges from 9 $\mathrm{mm} / \mathrm{s}$ at a distance of $2.5 \mathrm{~m}$ from the source location to $0.2 \mathrm{~mm} / \mathrm{s}$ at a distance of $60 \mathrm{~m}$ (Figure 8a). The range of these PPV values is similar to those reported in the literature (e.g. Auersch, 2010, and Auersch and Said, 2010).

The previously discussed analytical and empirical attenuation equations are also presented for comparison in Figure 8. The approximate power law $\mathrm{A} \propto \mathrm{r}^{-\mathrm{q}}$ was fitted to the data through a linear regression in the logarithmic plane, giving a straight line with slope $\mathrm{q}=1.282$ (Figure 8a). The value of the exponent is within the range $1.0 \div 1.6$ previously found for drop load tests by Auersch (2010). The comparison with the power law suggested by Sambuelli (2009), expressed by equation (9), is shown in Figure 8b. This power law, used for blasting operations, has not previously been applied to drop load experiments. Hence the following assumptions have been made to adapt the blasting law to the drop load tests performed in Pisa:

(1) the explosive mass is substituted by the mass of the falling weight $(Q=130 \mathrm{~kg})$;

(2) the rock density is substituted by the weighted average soil density of the subsoil profile of Pisa $\left(\rho=1886 \mathrm{~kg} / \mathrm{m}^{3}\right)$;

(3) a point source is assumed $\left(r_{0}=0.001 \mathrm{~m}\right)$;

(4) the excitation frequency is taken as $f=25 \mathrm{~Hz}$ (corresponding to a period of $T_{S}=0.04 \mathrm{~s}$ ) which is the central frequency at the closest geophone (refer to Figure 7, Geophone No.2); 
(5) the specific energy is derived from the principle of energy conservation for a $130 \mathrm{~kg}$ mass falling from 3 $\mathrm{m}$ of height $(\Phi=\mathrm{mgh} / \mathrm{m}=29.43 \mathrm{~J} / \mathrm{kg})$;

(6) an average Rayleigh wave velocity (obtained from the cross-hole shear wave velocity profile presented in Table 5) $V_{R}=226 \mathrm{~m} / \mathrm{s}$ is considered;

(7) $K=0.005$ is assumed as calibration factor.

Despite the differences in the nature of the tests, reasonable agreement is obtained between the field data and the predicted values, with an over-prediction of the PPV values close to the source. Further studies are needed to rigorously assess the use of equation (9) for drop load tests and to calibrate the parameter $K$ (set to 1 in Sambuelli, 2009, for blasting).

A final comparison is made against the complete attenuation law given by equation (8) (Figure 8c), with parameters listed in Table 2. The excitation period $T_{S}$ is the same as the one used in Sambuelli's equation for comparison and $H_{S}$ is the amplitude of the excitation considering equation (6) as source model and its input parameters presented in Table 6. The other input parameters of equation (8) $k, C$ and $\xi$ were calibrated on the near-field experimental data and the overall peak particle velocity decay with distance to obtain the closest match. The very good agreement between the complete law and the measured attenuation trend demonstrates the importance of the exponential attenuation component, related to the soil dissipative behaviour. However even the simpler power laws (Figure 8a-b) are able to reproduce the wave amplitude decay with sufficient accuracy for preliminary design purposes.
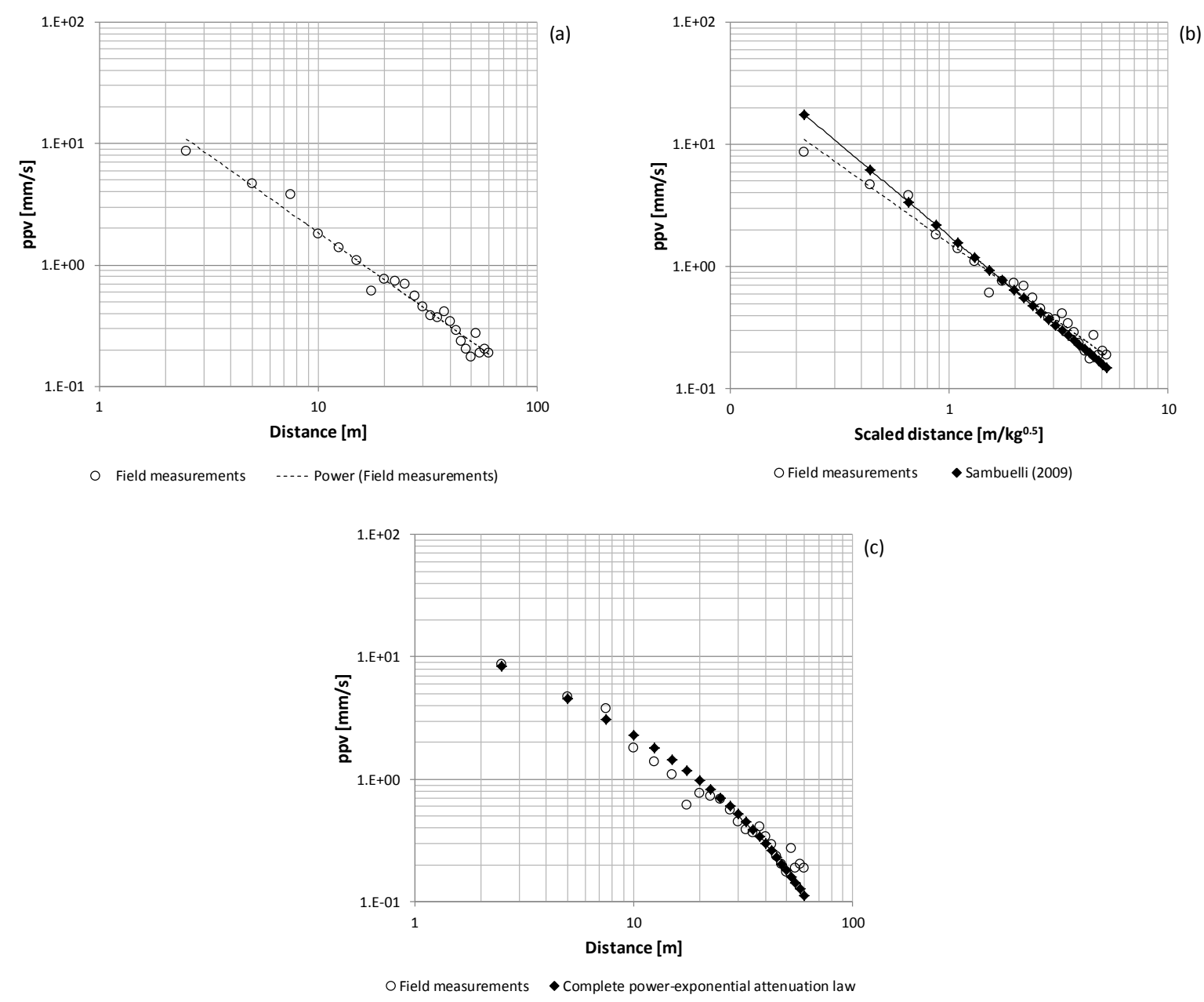

Figure 8 -Measured peak particle velocity with distance from the source and comparison with (a) power law, (b) power law for blasting (from Sambuelli, 2009), (c) complete power and exponential law

Table 2 - Input coefficients for the power-exponential attenuation law 


\begin{tabular}{lll}
\hline Parameter & Unit & Value \\
\hline$T_{S}$ & $\mathrm{~s}$ & 0.04 \\
$H_{S}$ & $\mathrm{~mm} / \mathrm{s}$ & 0.145 \\
$k$ & $/$ & 0.302 \\
$C$ & $/$ & 3800 \\
$n$ & $/$ & 0.75 \\
$m+p$ & $/$ & 1.4 \\
\hline
\end{tabular}

\section{Numerical model description}

Time-domain finite element simulations with hydro-mechanical coupling of the drop-load tests carried out in Pisa were performed with the code ICFEP (Potts \& Zdravkovic 1999). For the accurate representation of the impact-induced wave field a precise evaluation of the model input parameters is clearly of primary importance including: the extent of the soil domain to be modelled, appropriate soil parameters, absorbing boundary conditions and realistic representation of the disturbing source.

\subsection{Domain discretisation}

A two-dimensional axisymmetric configuration was used for the simulation of the drop-load tests as schematically illustrated in Figure 9. To account for the symmetry of the problem, the horizontal displacement is restricted along the left lateral boundary, while the standard viscous boundary condition (Lysmer and Kuhlemeyer, 1969), consisting of tangential and normal to boundary dashpots, is applied at the bottom and right lateral boundaries to absorb wave reflections. The water table was taken at a depth of $1.3 \mathrm{~m}$ from the ground surface applying a boundary condition of zero pore pressure at that depth. The instrumented distance investigated in the experimental drop load test extends to $60 \mathrm{~m}$ from the source, but, based on a preliminary parametric investigation, the mesh width was taken equal to $160 \mathrm{~m}$ to minimize the interaction of the right lateral mesh boundary with the generated wave field. Similarly, based on preliminary analyses, the mesh depth extends to $53 \mathrm{~m}$, as it was deemed important for the accurate representation of the surface wavefield to include the deeper deposits (i.e. layers BIV and C). Eight-noded quadrilateral solid elements were used to define the mesh. For the accurate representation of all frequencies produced by the dynamic load, there should be at least eight elements per the smallest Rayleigh wavelength considered in the analysis. This consideration led to a fine mesh discretisation of 9472 elements. 


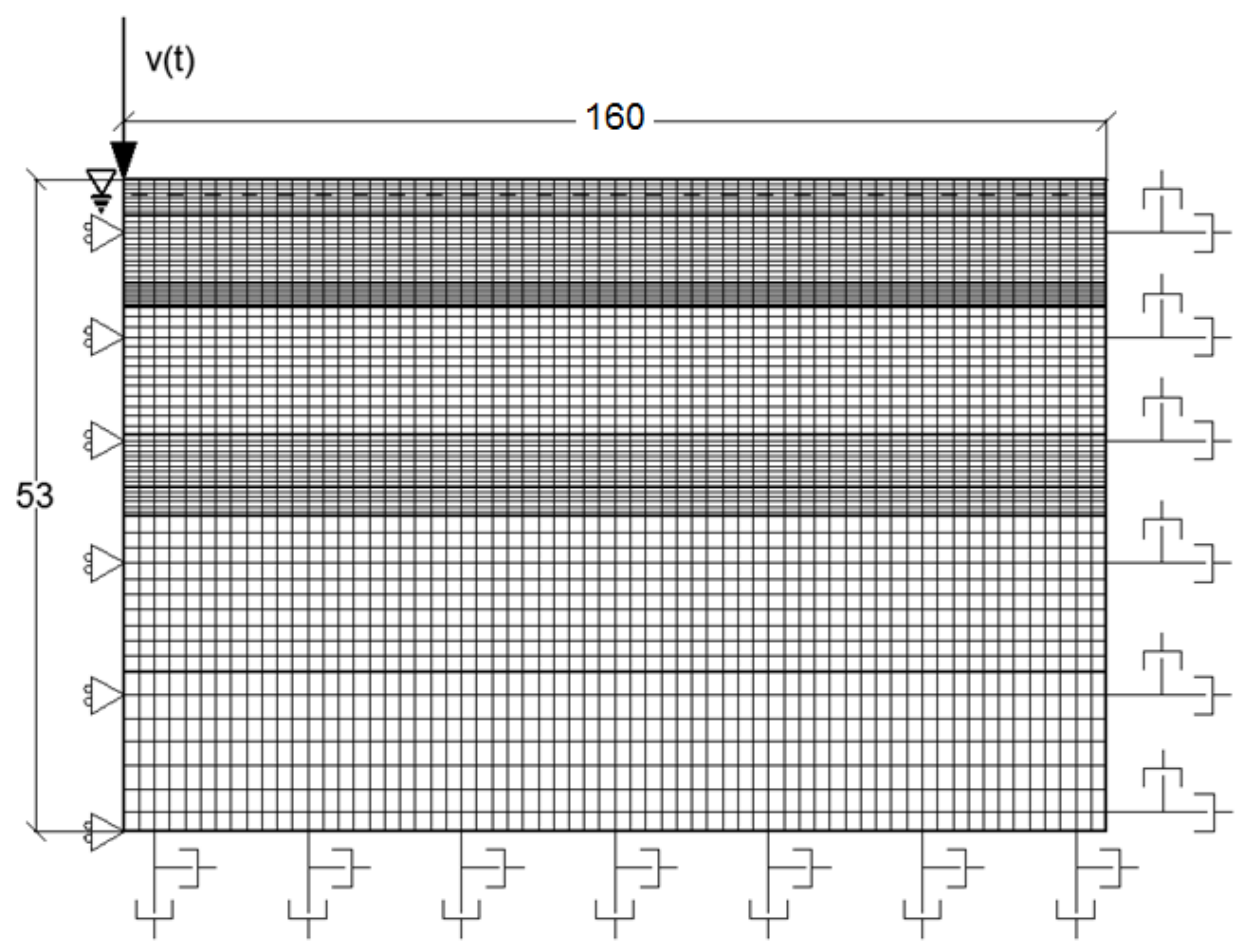

Figure 9 - Subsoil discretisation and boundary conditions (out of scale)

\subsection{Assigned soil properties}

As the stratigraphy of the subsoil beneath Piazza dei Miracoli is quite complex, various assumptions were made to perform the numerical simulations with ICFEP: (1) horizontal layer interfaces; (2) layer continuity in the horizontal direction; (3) and properties constant within each layer. As the strains developed as a consequence of the impact of the falling weight are generally small the soil was assumed to behave as linear visco-elastic material employing the properties shown in Table 3 and Table 4.

Table 3 - Soil properties used in the finite element analysis

\begin{tabular}{|c|c|c|c|c|c|c|c|c|}
\hline Layer & Description & Depth & Thickness & $\begin{array}{l}\gamma \\
\text { Bulk unit } \\
\text { weight }\end{array}$ & $\begin{array}{l}\text { E } \\
\text { Soil } \\
\text { stiffness }\end{array}$ & $\begin{array}{l}v \\
\text { Poisson's } \\
\text { Ratio }\end{array}$ & $\begin{array}{l}\xi * \\
\text { Target } \\
\text { damping } \\
\text { ratio }\end{array}$ & $\begin{array}{l}\text { K } \\
\text { Permeability }\end{array}$ \\
\hline & & {$[\mathrm{m}]$} & {$[\mathrm{m}]$} & {$\left[\mathrm{kN} / \mathrm{m}^{3}\right]$} & {$[\mathrm{MPa}]$} & [/] & {$[\%]$} & {$[\mathrm{m} / \mathrm{s}]$} \\
\hline MG & Silt & 0.0 & 3.0 & 19.00 & 124 & 0.33 & 7.0 & $1.0 \mathrm{E}-07$ \\
\hline A1 & Silt & 3.0 & 5.4 & 18.50 & 163 & 0.33 & 5.4 & $1.0 \mathrm{E}-07$ \\
\hline A2 & Upper Sand & 8.4 & 2.0 & 18.00 & 141 & 0.33 & 2.5 & $5.0 \mathrm{E}-07$ \\
\hline BI & Upper Clay & 10.4 & 10.4 & 16.75 & 102 & 0.33 & 3.1 & $9.0 \mathrm{E}-09$ \\
\hline BII & Intermediate Clay & 20.8 & 4.2 & 19.50 & 2920 & 0.33 & 2.0 & 8.0E-09 \\
\hline BIII & Intermediate Sand & 25.0 & 2.4 & 18.75 & 3051 & 0.33 & 2.0 & $5.0 \mathrm{E}-07$ \\
\hline BIV & Lower Clay & 27.4 & 12.6 & 18.00 & 226 & 0.33 & 2.0 & $8.0 \mathrm{E}-09$ \\
\hline C & Lower Sand & 40.0 & 13.0 & 20.00 & 783 & 0.33 & 2.0 & $5.0 \mathrm{E}-07$ \\
\hline
\end{tabular}

Table 4 - Partial saturation characteristics: bulk modulus of fluid [kPa] and correspondent saturation $S_{r}[\%]$ 


\begin{tabular}{llll}
\hline Layer & & $\boldsymbol{K}_{f}$ & $\boldsymbol{S}_{\boldsymbol{r}}$ \\
& Fluid Bulk Modulus & Saturation \\
\hline Layer MG & (above water table) & 9954.8 & $99.00 \%$ \\
Layer MG & $($ below water table) & 19819.8 & $99.50 \%$ \\
Layer A1 $\quad\left(V_{p}<1400 \mathrm{~m} / \mathrm{s}\right)$ & 592710.5 & $99.981 \%$ \\
Layer A1 $\quad\left(V_{p}>1400 \mathrm{~m} / \mathrm{s}\right)$ & $2.2 \mathrm{E} 6$ & $100.00 \%$ \\
Layers A2 $\div \mathrm{C}$ & $2.2 \mathrm{E} 6$ & $100.00 \%$ \\
\hline
\end{tabular}

Incomplete saturation of near-surface layers was also approximated in the analyses (Table 4) by appropriately adjusting the compressibility of the pore fluid for those layers. This was deemed important, as the compression wave velocity $\mathrm{V}_{\mathrm{P}}$ (recorded from cross-hole $\mathrm{CH}$ tests in Piazza dei Miracoli) was found to increase drastically from 750 to $1400 \mathrm{~m} / \mathrm{s}$ within the first few meters of the deposit (up to $6 \mathrm{~m}$ below ground level) and to then stabilise at some depth (Table 5). As stated in Yang and Sato (2000), P-wave velocity is strongly affected by the degree of saturation $S_{r}$ (even below water level) due to fluctuating water table, flooding or recharge of groundwater.

A normally dispersive profile with slight velocity inversion, retrieved from in situ tests, has been used in the numerical analysis. The assumed longitudinal and shear wave velocity profiles are reported in Table 5 The material damping of the soil profile was approximated with the Rayleigh damping formulation - equation (10) (amongst others Chopra, 2001):

$$
[C]=A[M]+B[K]
$$

Where $[M]$ and $[K]$ are the mass and the stiffness matrices respectively, while $\mathrm{A}$ and $\mathrm{B}$ are the mass proportional and the stiffness proportional damping coefficients respectively. These coefficients are related to the target damping ratio, $\xi^{*}$, through the following relationship:

$$
A=\frac{2 \xi^{*} \omega_{1} \omega_{n}}{\omega_{1}+\omega_{n}} \text { and } B=\frac{2 \xi^{*}}{\omega_{1}+\omega_{n}}
$$

Where $\omega_{1}$ and $\omega_{n}$ are the two frequencies defining the frequency range over which the damping is equal or lower than $\xi^{*}$. Clearly, the Rayleigh damping formulation is frequency dependant. However for the frequency range of interest in the present study, damping in soils is in reality almost independent of frequency. It is therefore common practice to try to get the appropriate almost constant "target" damping for the important frequencies of the problem (i.e. range $\omega_{l}$ to $\omega_{n}$ ). In this study $\omega_{l}$ was taken equal to the site's natural frequency and $\omega_{n}$ was set equal to the predominant frequency of the input motion. The target damping ratio was varied with depth (and considered constant within each layer) to match the damping ratio data obtained from SASW tests analysis (Foti, 2003) (Figure 10).

Table 5 - Wave velocity profiles [m/s] used for the numerical model

\begin{tabular}{lcc}
\hline Layer & $\boldsymbol{V}_{\boldsymbol{P}}$ & $\boldsymbol{V}_{\boldsymbol{S} \boldsymbol{V}}$ \\
\hline MG & 760 & 155 \\
A1 & 1370 & 180 \\
A2 & 1580 & 170 \\
BI & 1700 & 150 \\
BII & 1690 & 235
\end{tabular}




\begin{tabular}{lll} 
BIII & 1690 & 245 \\
BIV & 1670 & 215 \\
C & 1940 & 380 \\
\hline
\end{tabular}

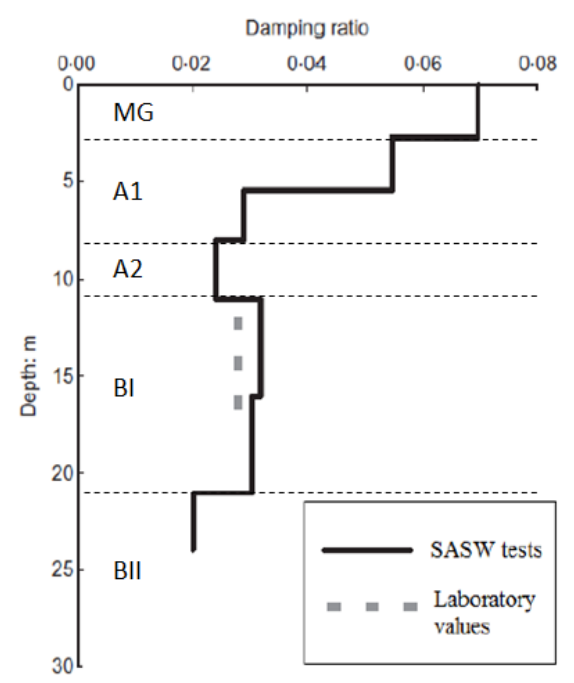

Figure 10 - Damping ratio profile with depth from SASW tests and from laboratory tests (based on Foti, 2003)

\subsection{Synthetic input source signal and time discretisation}

The impact source used in the tests performed in Piazza dei Miracoli, Pisa, was not monitored and thus no force time history was available. In order to model numerically the impact of the falling mass in the ground, an assumed velocity time history was applied in the numerical model in the form of a modified version of the Gabor wavelet (based on Semblat and Pecker, 2009), presented in equation (6), which approximated the induced velocity history in the ground employing the parameters shown in Table 6. The excitation was applied incrementally at the top left node of the model. As the wave attenuation modelling is an important aspect of this study, zero numerical damping was used by adopting for the time integration Newmark's average acceleration method (Newmark, 1959) with a time step $\Delta \mathrm{t}=0.002 \mathrm{sec}$.

\begin{tabular}{cll} 
Table & \multicolumn{3}{c}{ Source signal wavelet parame } \\
\cline { 2 - 3 } Parameter & Unit & Value \\
\hline$T_{S}$ & $\mathrm{~s}$ & 0.04 \\
$\alpha$ & $/$ & 7.0 \\
$\beta$ & $/$ & $1.55 \mathrm{E}-2$ \\
$\gamma$ & $/$ & 1.2 \\
$C_{b}$ & $\mathrm{~kg} \cdot \mathrm{m} / \mathrm{s}$ & 997.4 \\
\hline
\end{tabular}

\section{Results}

The outcome of the finite element simulation has been compared with the field measurements. As 24 geophones were used for the tests, an extensive data set was analysed. Three sample geophones are 
considered in the following to show a representative response for near-field, far-field and intermediate conditions.

\subsection{Comparison with the field data}

The experimental recordings at the reference geophones 2, 12 and 22 (at a distance of 5, 30 and $55 \mathrm{~m}$ respectively from the source) are compared to the numerical results both in time and frequency domains (Figure 11).

The plots show that, in particular in the near- and middle-field, the numerical signal highly resembles the experimental one. However waves of smaller amplitude (registered after the major tremor) due to wave reflections and refractions in the soil deposit are not well captured by the numerical model. In the far-field this successive wave and the minor tremor seem to be better reproduced, but a substantial temporal shift (i.e. faster wave-field propagation in the soil) is observed.

These inaccuracies in the response are mainly due to simplifications/assumptions used in the numerical model: for example uncertainties in the degree of soil saturation could have led to the faster predicted waves, while the use of a synthetic source signal, which is based a predominant frequency $(25 \mathrm{~Hz})$, cannot fully capture the full range of frequencies within the actual source signal.

In particular the influence of oscillations in the water table position and to the consequent effect of partial saturation may have played an important role. In this respect it is noted that the cross-hole test on which the model is based was performed in January 2000, whereas the drop load test was carried out in October 2000. Several repetitions of surface wave tests at the site of the Leaning Tower (February 2000, October 2000, July 2001) have shown a marked seasonal variability in the obtained dispersion curve for the frequency range 8$30 \mathrm{~Hz}$ which is associated to the top $10 \mathrm{~m}$ where the water table fluctuation may have an influence (Foti, 2014). 
Geophone No.2 $(r=5.0 \mathrm{~m})$
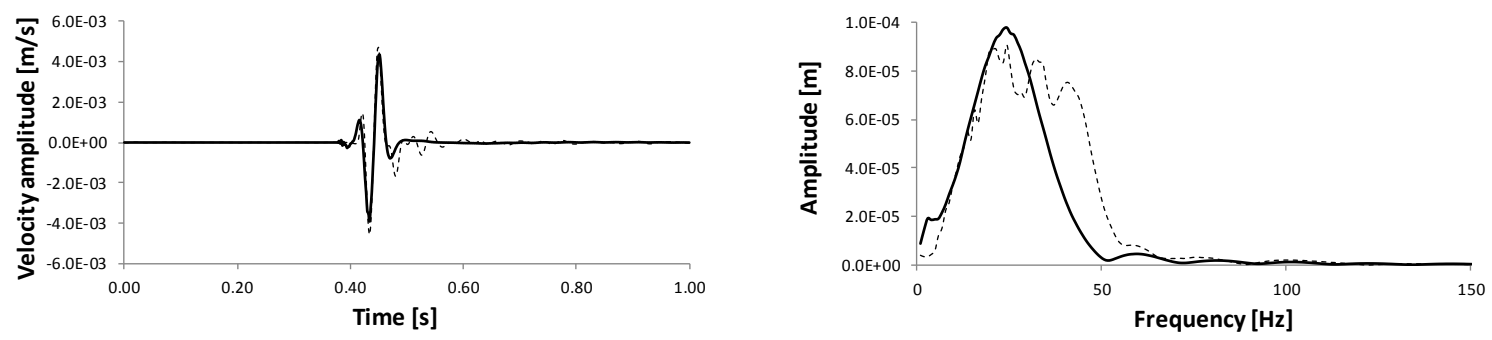

Geophone No.12 ( $\mathrm{r}=30.0 \mathrm{~m})$
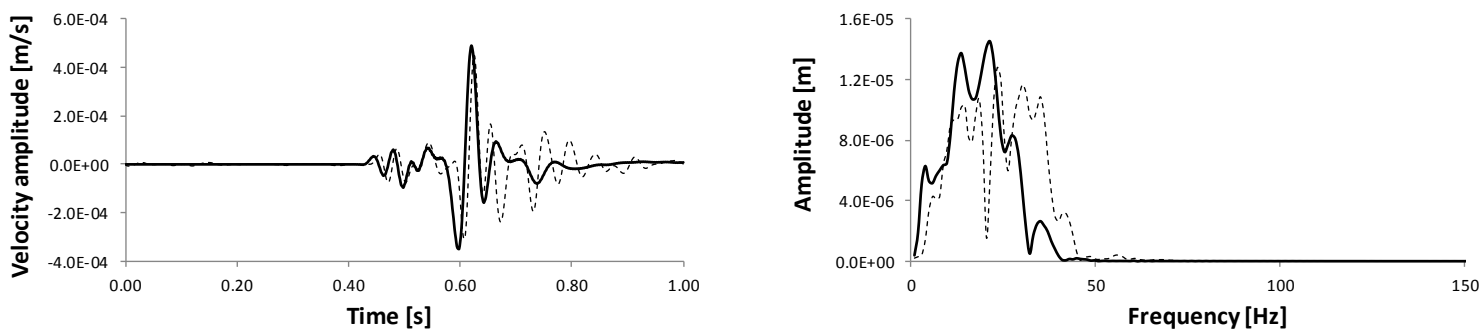

Geophone No.22 ( $r=55.0 \mathrm{~m})$
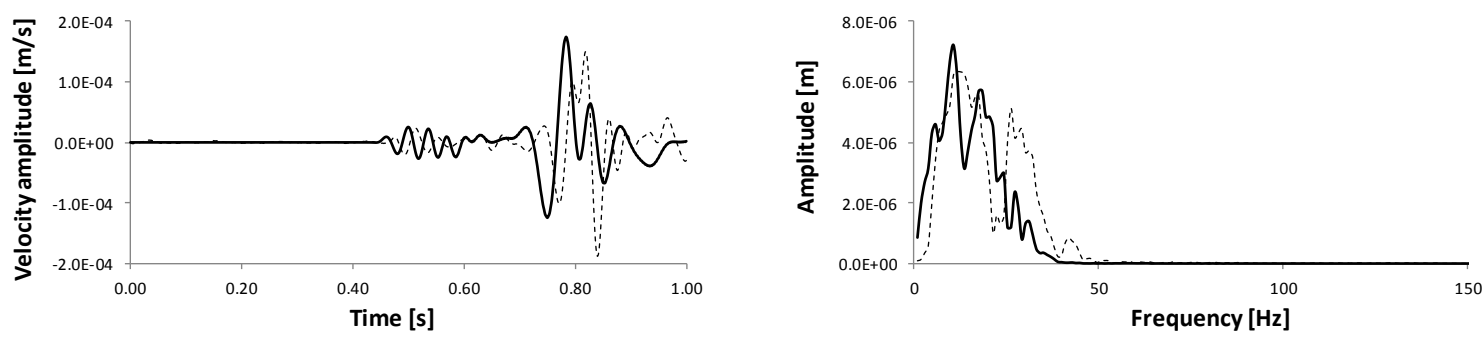

-..-- Field measurements - Numerical Prediction

Figure 11 - Comparison of the experimental and numerical time histories and relative Fourier spectra (at $r=5,30$ and $55 \mathrm{~m}$ from the source)

In Figure 12 the wave-field generated by the numerical drop load source is shown at different time instants. Vectors of incremental velocity are plotted with the soil stratigraphy annotated in the same plot. From the plots, the following can be appreciated:

- $\quad$ Instant $t=0.48 \mathrm{~s}$ : wave propagation in the vicinity of the source takes place mainly in the form of body waves which expand in a radial front, while further away at the surface a more complicated wave field appears, presumably due to the presence of Rayleigh waves ;

- Instant $\mathrm{t}=0.56 \mathrm{~s}$ : the wave front starts to deform in correspondence to the boundary between layersA2, sandy, and BI, clayey, reflecting the difference in soil properties and therefore in wave propagation velocity;

- Instant $t=0.60 \mathrm{~s}$ : a major wave reflection forms at the bottom boundary of layer BI due to the significant difference in shear wave velocity with layer BII. Overall, the wave field continues to expand its front;

- Instant $\mathrm{t}=0.72 \mathrm{~s}$ : a second reflection takes place at the interface between layers BIV and C that has a substantial impedance ratio $\left(\alpha_{z}=1.3\right)$. The wave front deforms in the upper layers and low wave energy is transmitted through layer $\mathrm{C}$. 

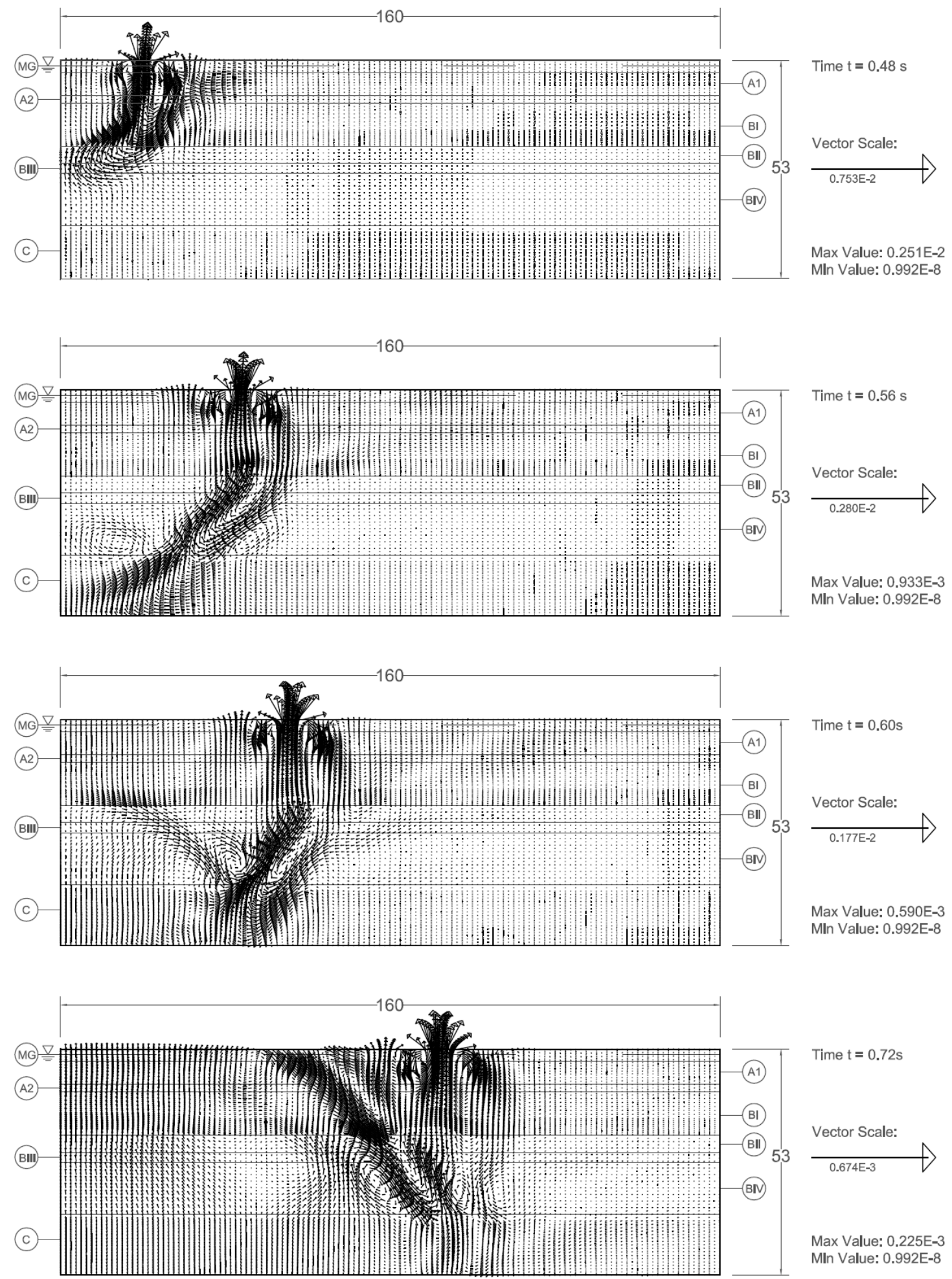

Figure 12 - Vectors of incremental displacement at different time instants (all measures are given in metres if not otherwise stated)

\subsection{Comparison of the PPV trend with literature equations}

The result of the numerical analysis in terms of peak particle velocity with distance is presented in Figure 13 and compared with the experimental decay. Despite the bias in the calculated frequency range and wave propagation velocity, the wave amplitude at the different distances is accurately modelled and the exponent 
$\mathrm{q}=1.272$ (considering an approximated power law) compares very favourably with the experimental value of 1.282 .

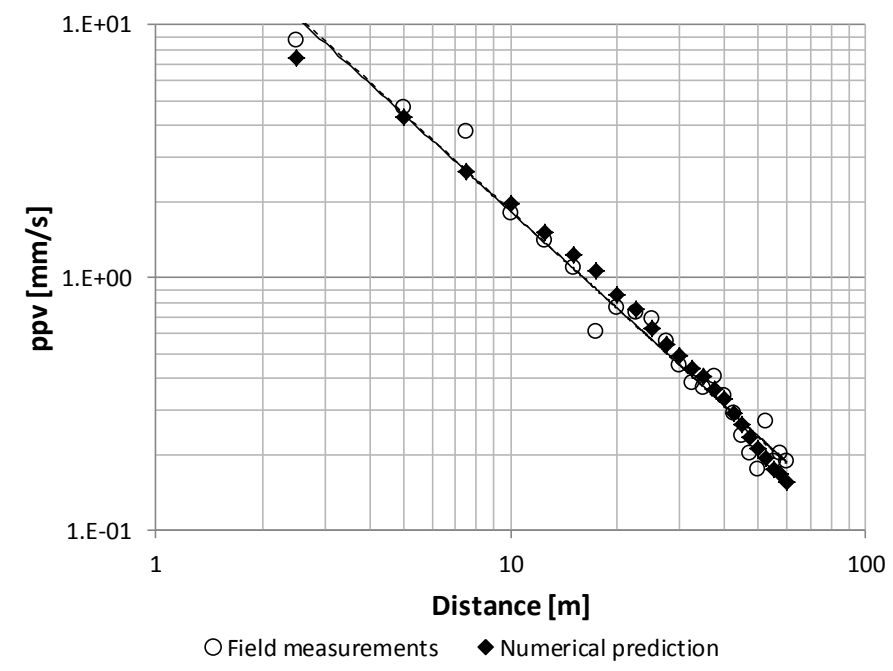

Figure 13 - Comparison of the experimental and numerical PPV attenuation curves. Exponential PPV decay is considered

A further comparison of the numerical PPV decay, presented in Figure 14, was performed against the power law suggested for blasting operations by Sambuelli (2009), expressed by equation (9) adopting the same assumptions as the ones used in the earlier comparison with the experimental data. The amplitude decay derived from the empirical equation predicts stronger wave attenuation in the ground than the numerical analysis. The empirical equation predicts PPV values that are more than twice those predicted by the numerical analysis in the near-field, while it gives lower PPV values in the far-field with the differences reaching $20 \%$.

The final comparison is made against the complete attenuation law given by equation (8). The same coefficients as the ones adopted for the comparison with the experimental data are also used for the comparison with the numerical analysis results. Figure 15 shows a very good agreement in the predicted PPV attenuation between the two approaches, highlighting once more the better performance of the complete attenuation law.

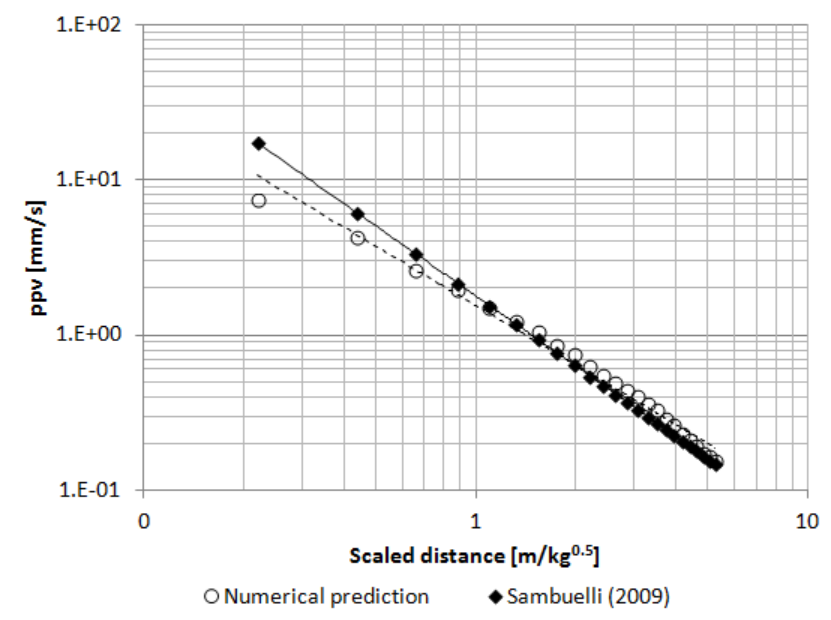

Figure 14 - Peak particle velocity attenuations with scaled distance SD - Comparison between numerical results and values obtained from equation (9) 


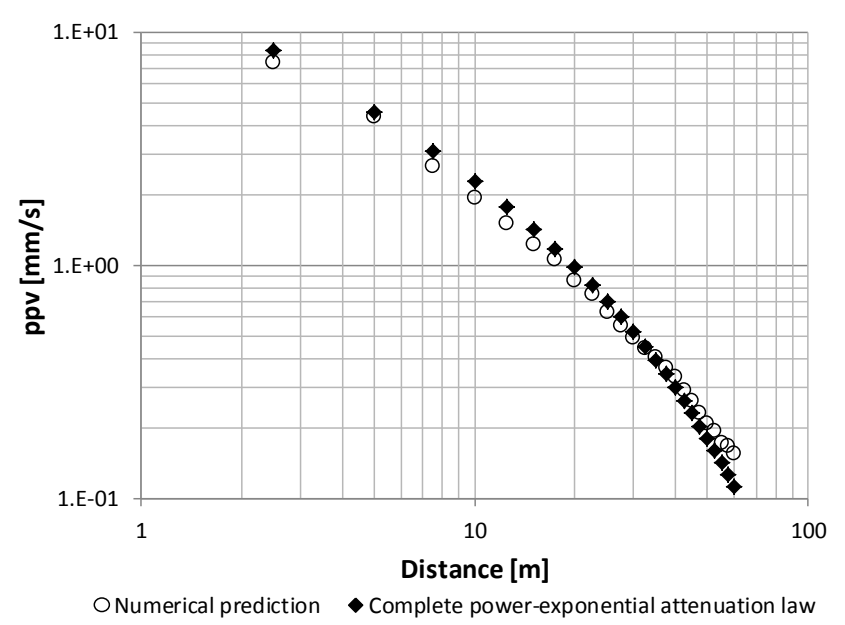

Figure 15 - Numerical peak particle velocity attenuation and accurate amplitude-distance curve given by equation (8) and coefficients as defined in Table 2

\section{Conclusions}

The main aim of this study is to investigate the attenuation of ground vibrations generated by drop load tests and to assess the validity of analytical and empirical expressions comparing them with the attenuation predicted by numerical analysis using as a reference field data from a well-documented case study.

The two main factors contributing to the attenuation of impact-induced waves in the ground, geometrical spreading and material damping, were shown to follow a power and exponential attenuation law respectively. Numerous equations to reproduce the decay of the waves with distance have been suggested in previous studies. A simplified power law, a complete law (consisting of exponential and power laws) and an attenuation law originally determined for blasting operations were examined in this study. All the three expressions exhibited satisfactory correspondence with the experimental monitoring of drop load tests carried out in Pisa, but the superiority of the complete law was clear.

An overview of the available analytical methodologies developed to study the soil response due to a weight falling on the ground is presented in terms of source simulation and generated wave field evaluation. The simplified hypotheses of impulse source and homogeneous soil proposed in previous studies are revised to obtain a more accurate representation of the disturbing action produced by drop load tests. A newly proposed expression has shown to successfully represent the impact source in the numerical simulation of the examined case study, but further validation through comparison with field data is needed to confirm its general applicability.

The numerical simulation of the experimental case study was performed in time-domain with the finite element code ICFEP, as an independent assessment of the existing analytical attenuation expressions. To model the source, velocities induced in the ground by the impact were approximated through a modified formulation of the Gabor wavelet, proposed for the first time in this study (equation (6)). Despite the model simplifications and assumptions, the agreement of the numerical results with the experimental recordings shows how a very good prediction of the expected ground vibrations can be achieved on the basis of a good site characterisation and monitoring relatively close to the source. The numerical outcome and the PPV attenuation equations were subsequently compared to assess the accuracy of simple analytical and empirical approaches which are widely used in engineering practice, achieving in particular a high degree of resemblance with the complete attenuation law.

\section{References}

Abe, S., Kobayashi, Y. \& Ikawa, T. (1990) Seismic characteristics of the weight-dropping source. Journal of Physics of the Earth. 38 (3), 189-212. 
Achenbach, J.D. (1999) Wave propagation in elastic soils. Eight edition. Amsterdam, The Netherlands, Elsevier.

Auersch, L. (2010) Technically Induced Surface Wave Fields, Part I: Measured Attenuation and Theoretical AmplitudeDistance Laws. Bulletin of the Seismological Society of America. 100 (4), 1528-1539.

Auersch, L. \& Said, S. (2010) Attenuation of ground vibrations due to different technical sources. Earthquake Engineering and Engineering Vibration. 9 (3), 337-344.

Burland, J.B., Jamiolkowski, M.B. \& Viggiani, C. (2009) Leaning Tower of Pisa: Behaviour after Stabilization Operations. International Journal of Geoengineering Case histories, Vol. 1 (3), 156-169.

Burland, J.B., Jamiolkowski, M.B. \& Viggiani, C. (2003) The stabilisation of the Leaning Tower of Pisa. Soils and Foundations Vol. 43 (5), 63-80.

Burland, J.B., Jamiolkowski, M.B. \& Viggiani, C. (1998) Stabilising the leaning tower of Pisa. Bulletin of Engineering Geology and the Environment. 57 (1), 91-99.

Chopra, A.K. (2001) Dynamics of Structures: Theory and Applications to Earthquake Engineering. Prentice Hall, Englewood Cliffs, New Jersey.

Costanzo, D., Jamiolkowski, M., Lancellotta, R. \& Pepe, M.C. (1994) Leaning Tower of Pisa-Description of the behaviour. Banquet Lecture.

Foti S. (2014), "Personal communication".

Foti, S. (2003) Small-strain stiffness and damping ratio of Pisa clay from surface wave tests. Geotechnique. 53 (5), $455-$ 461.

Foti S., Lai C.G., Rix G.J. \& Strobbia C. (2014) Surface Wave Methods for Near-Surface Site Characterization, CRC Press, Boca Raton, Florida (USA), 487 pp.

Gucunski, N. \& Woods, R.D. (1992) Numerical simulation of the SASW test. Soil Dynamics and Earthquake Engineering. 11 (4), 213-227.

Hollandsworth, P.E. \& Busby, H.R. (1989) Impact force identification using the general inverse technique. International Journal of Impact Engineering. 8 (4), 315-322.

Jamiolkowski, M. \& Pepe, M. C. (2001) Vertical yield stress of Pisa clay from piezocone tests. Journal of Geotechnical and Geoenvironmental Engineering. 127 (10), 893-897.

Jamiolkowski, M., Lancellotta, R. \& Pepe, C. (1993) Leaning Tower of Pisa-Updated Information. Third International Conference on Case Histories in Geotechnical Engineering.

Lamb, H. (1904) On the propagation of tremors over the surface of an elastic solid. Philosophical Transactions of the Royal Society of London. Series A, Containing papers of a mathematical or physical character. 203, 1-42.

Lo Presti, D.C.F., Jamiolkowski, M. \& Pepe, M. (2003) Geotechnical characterisation of the subsoil of Pisa Tower. Characterisation and Engineering Properties of Natural Soils, Swets \& Zeitlinger, Lisse. pp. 909-946.

Lysmer J. \& Kuhlemeyer R.L. (1969) Finite dynamic model for infinite media. Journal of the Engineering Mechanics Division, ASCE, Vol. 95 (4), 859-877.

Martin, M.T. \& Doyle, J.F. (1996) Impact force identification from wave propagation responses. International Journal of Impact Engineering. 18(1), 65-77.

Miller, G.F., \& Pursey, H. (1955). On the partition of energy between elastic waves in a semi-infinite solid. Proceedings of the Royal Society of London. Series A. Mathematical and Physical Sciences, 233 (1192), 55-69.

Mooney, H.M. (1976) The seismic wave system from a surface impact. Geophysics. 41 (2), 243-265.

Mooney, H.M. (1974) Some numerical solutions for Lamb's problem. Bulletin of the Seismological Society of America. 64 (2), 473-491.

Newmark N.M. (1959) A method of computation for structural dynamics. Journal of Engineering Mechanics Division, ASCE. 85, 67-94.

Pekeris, C. (1955) The seismic surface pulse. Proceedings of the National Academy of Sciences of the United States of America. 41 (7), 469.

Potts, D.M. \& Zdravković, L. (2001) Finite element analysis in geotechnical engineering: theory. Thomas Telford.

Rampello, S. \& Callisto, L. (1998) A study on the subsoil of the Tower of Pisa based on results from standard and highquality samples. Canadian Geotechnical Journal. 35 (6), 1074-1092. 
Sambuelli, L. (2009) Theoretical derivation of a peak particle velocity-distance law for the prediction of vibrations from blasting. Rock Mechanics and Rock Engineering. 42 (3), 547-556.

Semblat, J.J. \& Pecker, A. (2009) Waves and vibrations in soils. Iuss Press.

Yang, J. \& Sato, T. (2000) Interpretation of seismic vertical amplification observed at an array site. Bulletin of the Seismological Society of America. 90 (2), 275-285.

Zerwer, A., Cascante, G. \& Hutchinson, J. (2002) Parameter estimation in finite element simulations of Rayleigh waves. Journal of Geotechnical and Geoenvironmental Engineering. 128 (3), 250-261.

\section{Figure Captions}

Figure 1 - Drop load test apparatus used for experimental tests in Pisa

Figure 2 - Experimental setup for multistation SASW tests

Figure 3 - Analytical source representations in terms of particle velocity: (a) Heaviside step unit function (Pekeris, 1955); (b) Dirac Delta function (Mooney, 1974); (c) Sinusoidal function (Mooney, 1974); and (d) Sinusoidal function (Abe et al., 1990)

Figure 4 - Modified Gabor wavelet

Figure 5 - Indicative stratigraphy retrieved in Piazza dei Miracoli, Pisa

Figure 6 - Location of seismic tests at the Leaning Tower of Pisa site

Figure 7 - Velocity time histories recorded at $r=5,30$ and $55 \mathrm{~m}$ from the source and corresponding Fourier spectra

Figure 8 - Measured peak particle velocity with distance from the source and comparison with (a) power law, (b) power law for blasting (from Sambuelli, 2009), (c) complete power and exponential law

Figure 9 - Subsoil discretisation and boundary conditions (out of scale)

Figure 10 - Damping ratio profile with depth from SASW tests and from laboratory tests (based on Foti, 2003)

Figure 11 - Comparison of the experimental and numerical time histories and relative Fourier spectra $($ at $\mathrm{r}=$ 5,30 and $55 \mathrm{~m}$ from the source)

Figure 12 - Vectors of incremental displacement at different time instants (all measures are given in metres if not otherwise stated)

Figure 13 - Comparison of the experimental and numerical PPV attenuation curves. Exponential PPV decay is considered

Figure 14 - Peak particle velocity attenuations with scaled distance SD - Comparison between numerical results and values obtained from equation (9)

Figure 15 - Numerical peak particle velocity attenuation and accurate amplitude-distance curve given by equation (8) and coefficients as defined in Table 2 